\title{
A computer-based renewable resource management system for a construction company
}

https://doi.org/10.1515/eng-2018-0062

Received Apr 14, 2018; accepted Jun 05, 2018

\begin{abstract}
The basic operation of a construction company involves the execution of tasks (building structures or building works) on sites. These projects are linked by the common resources of a building company used for the execution of different orders. The scheduling of a construction company programme is a continuous process with a dynamically changing look-ahead and scope of works. Decisions made on site by junior managers are based on their experience and intuition and are attempts at purposeful regulation - adaptation of the operative plan to the directive schedule, agreed with the investor, considering the progress of work. The quality of management decisions can be improved by implementing computer-based decision-supporting systems.
\end{abstract}

\section{Introduction}

Most research on time and cost optimisation of construction activities adopts the perspective of a single project [5, $10,14]$. Similarly, identification of factors and risks affecting duration, cost and quality of construction processes is typically conducted per project $[9,16]$. The literature on planning and optimisation of construction operations of an entire construction organisation is scarce [11]. The role of the management staff of a construction company is to ensure the maximum use of its resources but, under market conditions, it is very difficult to maintain balance between the production capacity of a company and the portfolio of orders [15]. The balance can be reached by a relevant tender strategy to get more orders [2] or by renting the company resources (working teams and building machines).

The company profit can be maximised following the rule of effectiveness, which identifies rational methods of

\footnotetext{
*Corresponding Author: Sławomir Biruk: Lublin University of Technology; Faculty of Civil Engineering and Architecture, Nadbystrzycka 38D; 20-618 Lublin, Poland; Email: s.biruk@pollub.pl
}

allocating limited resources among competitive objectives. Although the scope of work is known at the project planning stage and it is possible to estimate the time and cost of each construction process and the whole project, production programme scheduling in a construction company is a continuous process with a dynamically changing lookahead and scope of works. New works (objects) appear in the portfolio of the company orders. The majority of scientific works related to optimisation of use of construction company resources applies to the methods of scheduling individual construction projects, considering limitations in availability of resources. Designing an optimum schedule for a single building structure (e.g. with a minimum construction cycle) and its implementation according to the schedule do not guarantee the effective operation of a construction company but it can help to make a decision about joining another project in a short-term horizon.

A company can be successful when it rationally involves its resources in making the commissioned tasks that will provide a surplus of revenue over the costs of its working systems, by adapting to the market requirements and following the rules of marketing $[7,12]$. A project execution time and its quality are among competitive factors under market conditions.

The production schedule of a construction company is developed based on a portfolio of orders accepted for execution. The purpose of developing production schedules is to harmonise the work done on all sites. They make the basis for developing demand schedules for construction materials, operation of equipment, workforce and financial plans. Such schedules are usually developed periodically and then updated as new orders appear. The random nature of construction production may entail the need for them to be individually updated. The purpose of a production schedule is to ensure continuous operation of active resources and timely completion of work. In many cases the objectives are contradictary. Production schedules may quickly become outdated, which means that schedules with a shorter time horizon should ensure a higher degree of harmonisation of work and a high degree of using the executive potential of a construction company, while long-term schedules may accept the discon- 
tinuation of the work of construction teams. A construction company develops a construction schedule which is further updated and details are introduced as works proceed. Detailed scheduling should cover a period from 2 to 5 weeks and it should be a cyclical process. It ensures uniform use of resources and reduces the degree of uncertainty when construction processes are executed. Weekly schedules are necessary not only for the management of construction teams' work but they are also used by site inspectors and suppliers of construction products. They are established in weekly meetings organised by the site manager [1]. The meetings are devoted to the identification of the progress of processes and available resources, and the appointment of processes to be executed based on the evaluation of the degree of the project objective completion. Following some analyses, resources are allocated and an updated construction schedule is designed [6].

The operation of a construction company can be described as a change in the system status (quantity of available resources, deadlines for starting and completing processes or certain stages or whole projects) caused by management decisions, with a simultaneous impact of random events on its operation [18]:

$$
\mathbf{S}_{l+1}=\left[\mathbf{C}_{l}+\mathbf{R}\right] \cdot \mathbf{S}_{l}
$$

where: $\mathbf{R}$ stands for the impact of risk factors (e.g. failures of construction materials, poor weather conditions), $\mathbf{C}_{l}-$ decisions made at stage $l$, and $\bullet$ represents the impact of risk factors and decisions made in status $\mathbf{S}_{l}$ on status $\mathbf{S}_{l+1}$.

At the stage of operative planning decisions are made by junior managers. An organising engineer with relevant seniority can be a good planner. Decisions based on experience and intuition are attempts at purposeful regulation - adaptation of the operative plan to the directive plan, which may have lost its validity. The decisions are not always optimal with regard to the complexity of decision-making issues and the need to collect and analyse a lot of data. The quality of management decisions can be improved by employing optimising methods and computer-based decision-supporting systems [3, 17]. A computer-based system of managing construction company resources should allow for daily updates of the system status based on information communicated from the sites, and making corrected decisions taking into account the previous progress of work on all sites. The purpose is to implement tasks that will help to stick to deadlines for completing construction stages [13].

\section{Renewable resource management system for a construction company}

The proposed renewable resource management system for a construction company (RRMSCC) enables a change in the status of the modelled contractor's working system by:

- entering of new orders,

- changing availability of renewable resources caused by construction equipment failure or employment of new construction teams,

- closing of executed processes,

- passing new processes for implementation, considering availability of renewable resources.

A new order is modelled with an incidence matrix, reflecting the process and organisational relationship of an order accepted for implementation. An intended, deterministic duration and weight (priority) are assigned to each process. The parameters are used in some resource allocation rules. Based on the intended process execution times and the current status of the system clock corresponding to the date of accepting a project for execution, the scheduled completion deadline is calculated - not including the availability of renewable resources.

In the first step, the input is to be provided. This takes the form of information on the projects currently underway: network models of each project with information on the actual progress of works, as well as information on type and number of resources both engaged and available. These are the boundary conditions.

When all previous stages of a process have been completed and renewable resources are available in quantities necessary to execute a process, the process is included in the collection of processes that can be started. A decisionmaker selects one process for execution. This selection may be prompted by a resource management system that uses heuristic rules for resource allocation, but the final choice, considering process sequence and resource availability, belongs to the decision-maker. With not enough inhouse resources at hand, the decision-maker may resort to subcontracting.

The process completion date is to be defined according to the information directly from the building sites. The start and finish of a process are to be actual dates, and process durations may be different than assumed in the original schedule. Some examples of schedules generated by RRMSCC are presented in Figures 1-4. 
The most common priority rules of allocating resources in project scheduling have been implemented in the RRMSCC [4, 8]:

- The decision-maker identifies the priority. The value of the priority (taking a value of any natural number) can be identified based on the subjective evaluation of the contractor managing the resources and based on process cost, its criticality index or rank positional weight.

- Most immediate successors (MIS).

- Shortest processing time (SPT), established based on the scheduled process time.

- First-Come, First-Served (FCFS).

- Minimum slack (MSLK). It is a dynamic rule because the time reserve is calculated based on the actual duration of the completed processes (entered in the system by the decision-maker) and planned duration of processes not yet completed. The total process time reserve varies depending on the previous progress of the project under random conditions but also on the availability of resources and the method of their allocation.

- Earliest finish time (EFT). The finish time for each process is calculated as the total of its valid starting time and scheduled duration.

- Maximum process delay $(M D P)$. The process delay is calculated as the difference between the scheduled starting time (calculated for a deterministic model) and the valid resource allocation date.

- Resource equivalent duration (RED). With regard to different kinds of resources, weights (resource use costs) $v_{j}$ were allocated to them $j=1,2, \ldots, m$, and the process priority $i, i=1,2, \ldots, n$, is calculated as follows:

$$
R E D_{i}=t_{i} \cdot \sum_{j=1}^{m} v_{j} \cdot r_{i j}
$$

where $r_{i j}$ stands for the number of $j$ type resources necessary to complete process $i$ within the intended deadline $t_{i}$.

- Greatest resource utilisation (GRU) which selects a group of processes to be implemented, ensuring maximisation of the expression (use of resources):

$$
\max : \sum_{i \in A} \sum_{j=1}^{m} \delta_{i} \cdot v_{j} \cdot r_{i j}
$$

where $\delta_{i} \in\{0,1\}$ equals 1 , when process $i$ is passed for implementation; otherwise it is $0 . A$ stands for a collection of processes whose predecessors had been completed by the time the decision on passing a process for execution was made and no resources had been allocated.

- Random (RAN), according to which processes to be executed are selected randomly from a collection of processes that can be started. Any time a process is passed for execution, the availability of resources is updated and random selection repeated until the collection of processes that can be started is empty.

When there are several processes which can be started (all previous processes have been completed) but only some of them can be passed for execution due to a limited number of resource units, and the selected priority rule does not decide which process should be passed for execution, the selection is based on the weight assigned by the decision-maker. The weight can take a value of any natural number. When several processes have the same weight value, the process is selected randomly.

Information about the execution progress of company orders are collected in the RRMSCC system as the following output files:

1. A file containing the scheduled and actual dates of starting and completing of each project.

2. A file containing the scheduled and actual dates of starting and completing of all project processes and - additionally - the earliest possible starting times based on the previous progress and completions, being a total of the actual starting date and scheduled process execution times. The actual starting time of a process is defined as the earliest possible starting date, i.e. all its predecessors have been completed. Selection of a decision maker and allocation of resources to another process may result in its delayed start and exceeding the possible deadline.

3. A file containing a number of relocation cases from one site to another for each resource type.

4. Separate files for each type of resource containing information about the duration of periods in which a specific number of resource units was used and frequency of using the resource on a specific level.

5. File containing data about the number of resource units used on each working day.

6. File containing statistics of external (rented) resources, i.e. quantity and time of their use.

An analysis of results (collected in output data files) will help the decision-maker to analyse the progress of work and investigate the causes of non-compliance of schedules developed at the planning stage with the actual course of works on sites. 


\section{Examples of scheduling construction processes using RRMSCC system}

The RRMSCC develops a schedule of works following the decisions made. In Figure 1 the completed processes are marked in black, processes in progress are marked in red while those scheduled for execution at a later time are marked in blue. Assuming that the weights of three renewable resources amount to $v_{1}=0.1, v_{2}=0.2$ and $v_{3}=0.3$ respectively, and the availability of resources on day 3 is $r_{1}=8, r_{2}=7$ and $r_{3}=10$ units (the demand for the resources to execute the processes is presented in Table 1), the greatest resource utilisation $(G R U)$ rule suggests passing the following processes for execution: process 6 on site 1 and process 2 on site 2 (maximisation of expression 3 ), marked in yellow in Figure 1. Green highlighting marks the processes whose predecessors have been completed.

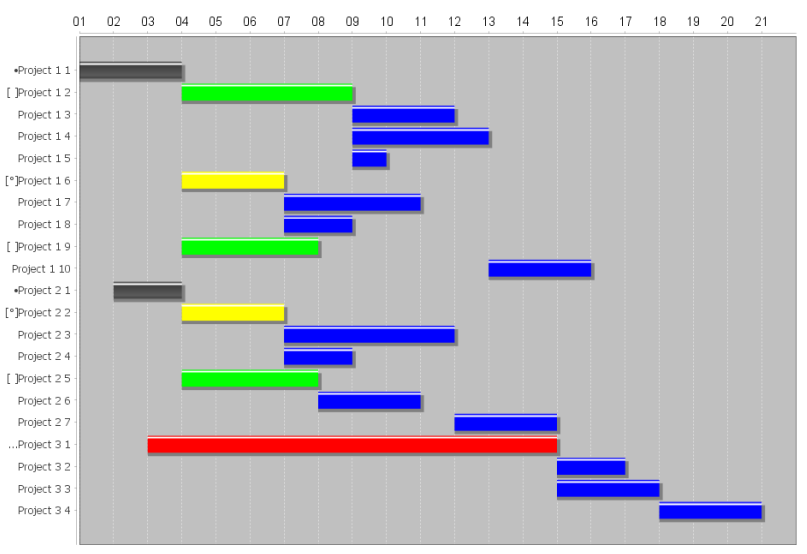

Figure 1: Sample of a company order execution schedule (RRMSCC screenshot).

Table 1: Demanded number of resource units to complete construction processes (examples and description in the text).

\begin{tabular}{ccccc}
\hline Site & Process & $\begin{array}{c}\text { Demand } \\
\text { for } \\
\text { resource 1 }\end{array}$ & $\begin{array}{c}\text { Demand } \\
\text { for } \\
\text { resource 2 }\end{array}$ & $\begin{array}{c}\text { Demand } \\
\text { for } \\
\text { resource 3 }\end{array}$ \\
\hline 1 & 2 & 3 & 5 & 7 \\
6 & 2 & 3 & 8 & \\
& 9 & 6 & 2 & 5 \\
\hline 2 & 2 & 4 & 3 & 2 \\
& 5 & 2 & 1 & 3 \\
\hline
\end{tabular}

To ensure the effective management of contractor's renewable resources, a central warehouse of resources and site warehouses were implemented in the system. Units of a resource remain in the site warehouse until the last process using the resource has been completed. When a decision is made to pass a process for execution, the decisionmaker considers the need to relocate units of resources (construction teams and equipment) from one site to another. The system remembers the number of cases of relocation.

The possibility of resource reservation on sites is a system element which caters for specific nature of construction projects. Different reservation times are entered for individual resources. The resource units stay on the site provided that they will be necessary to complete other processes on the site, however the fact that they are not currently used is recorded in the system as standby time. When the reservation period expires, the resource units become available for other sites. The resource reservation option is intended for resources whose cost of transport from one site to another is high, e.g. excavators, cranes and other heavy construction equipment.

The following example illustrating resource reservation options assumes that the quantities of resources given in Table 2 are necessary to execute processes on sites. Resource type 1 was assumed to be unlimited, while availability of resource 2 is 5 units. Starting execution of process 1 (Figure 2) resulted in reserving 3 units of resource 1 and 2 (each) on site 1. Using the rule of the shortest processing time (SPT) for deadline 3 results in a recommendation to start the shortest process (process 3 on site 2). In such a case only 1 unit of resource type 2 will remain in the central warehouse and process 2 (the shortest of all) cannot start on site 2. The shortest processes, i.e. 2 and 4 on site 1 (Figure 2) should be passed for execution because their initiation depends on the availability of resource type 2 : reserved on site 1, 3 units and 1 unit from the central warehouse. Process 3 cannot begin due to a lack of resource type 2.

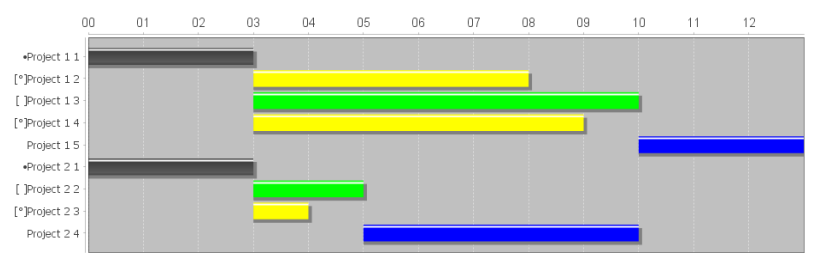

Figure 2: Project execution schedules in the example with reserving availability of resources on site according to the SPT rule. 
Table 2: Number of resource units necessary to execute construction processes - resource reservation option.

\begin{tabular}{cccccccc}
\hline Site & Process & Demand for resource & Demand for resource & Site & Process & Demand for resource & Demand for resource \\
& & 1 & 2 & & & 1 & 2 \\
\hline 1 & 1 & 3 & 3 & 2 & 1 & 0 & 0 \\
& 2 & 0 & 1 & & 2 & 3 & 2 \\
& 3 & 2 & 2 & 3 & 3 & 1 \\
\hline
\end{tabular}

Table 3: Sample data illustrating the scheduling horizon concept.

\begin{tabular}{|c|c|c|c|c|c|c|c|c|c|}
\hline $\begin{array}{l}\text { Construction } \\
\text { project }\end{array}$ & Process & $\begin{array}{l}\text { Process } \\
\text { execution } \\
\text { time }\end{array}$ & $\begin{array}{l}\text { Demand } \\
\text { for } \\
\text { resource } 1\end{array}$ & $\begin{array}{l}\text { Resource } 1 \\
\text { weight }\end{array}$ & $\begin{array}{c}\text { Demand } \\
\text { for } \\
\text { resource 2 }\end{array}$ & $\begin{array}{c}\text { Resource } 2 \\
\text { weight }\end{array}$ & $\begin{array}{c}\text { Demand } \\
\text { for } \\
\text { resource } 3\end{array}$ & $\begin{array}{c}\text { Resource } 3 \\
\text { weight }\end{array}$ & $\begin{array}{c}\text { RED } \\
\text { priority } \\
\text { value }\end{array}$ \\
\hline \multirow[t]{4}{*}{1} & 1 & 8 & 5 & 6 & 7 & 3 & 3 & 1 & 432 \\
\hline & 2 & 3 & 6 & & 5 & & 1 & & 156 \\
\hline & 3 & 4 & 4 & & 3 & & 1 & & 136 \\
\hline & 4 & 5 & 2 & & 8 & & 5 & & 205 \\
\hline \multirow[t]{3}{*}{2} & 1 & 8 & 6 & & 2 & & 8 & & 400 \\
\hline & 2 & 4 & 3 & & 2 & & 4 & & 84 \\
\hline & 3 & 5 & 2 & & 1 & & 2 & & 68 \\
\hline \multirow[t]{2}{*}{3} & 1 & 6 & 2 & & 5 & & 3 & & 180 \\
\hline & 2 & 4 & 8 & & 7 & & 5 & & 296 \\
\hline
\end{tabular}

Another option of the system resulting from specificity of construction engineering (long process execution times) is the possibility of introducing a look ahead $\Delta t$ (model parameter). Within the $t_{l}$ deadline of making decisions about the allocation of resources, a common list of processes is developed including:

1. processes which can be executed, all of whose predecessors were completed and no resources have been allocated to them yet,

2. direct successors of initiated processes whose scheduling has been completed in the acquired look-ahead, i.e. by $t_{l}+\Delta t$.

At the stage of resource allocation, resources released from processes scheduled for completion in the $t_{l}+\Delta t$ time interval are also taken into account.

Considering direct successors of the initiated processes in resource allocation ensures a higher degree of harmonisation of work whose scheduling suffers the lowest risk (the highest certainty of execution within the scheduled deadline).

In the example illustrating the use of the look-ahead concept, the assumed data include process execution times, number of units of necessary resources and their weight as in Table 3. It was assumed that $\Delta t=5$ and that the level of availability of resources equals: $r_{1}=13$, $r_{2}=14$ and $r_{3}=14$ units.

Within the decision-making deadline $t_{l}=3$, the completion of process 1 on site 1 and process 1 on site 3 are

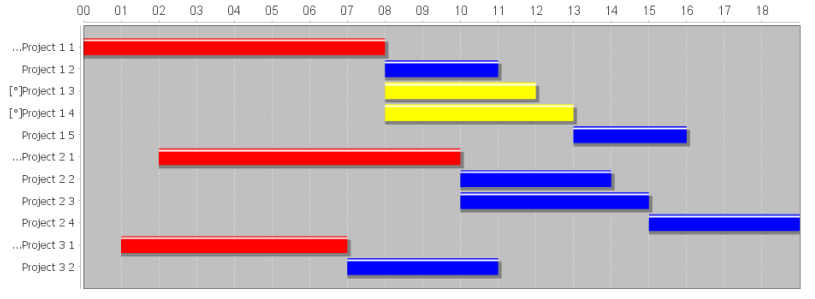

Figure 3: Order execution schedule - example with look-ahead; decision on resource allocation made within deadline $t_{l}=3$.

taken into account, and hence resource types 1, 2 and 3 will be available in 7, 12 and 6 units, respectively, by date 8. The $R E D$ rule recommends passing process 4 on site 1 as the first one to be executed due to the highest priority value amounting to $R E D_{14}=205$ among all processes following process 1 on site 1 (Figure 3 ). The availability of resources 1, 2 and 3 will then be 5, 4 and 1 unit respectively. Consequently, process 3 on site 1 will be passed for execution instead of process 2 , despite the fact that $R E D_{12}>$ $R E D_{13}$. Process 2 on site 3 cannot be executed due to the expected lack of resources.

For the decision on allocation of resources within deadline $t_{l}=5$, the expected availability of each type of resource on day 10 will be 13,14 and 14 units, respectively, which makes it possible to start process 2 on site 3 with $R E D_{31}=296$. Passing the process for execution will reduce the stock of available resources to 5, 7 and 9 units, respectively. Process 3 on site 1 with $R E D_{13}=156$ will be 
selected as the second one. The number of available resourced drops to 1, 4 and 8 units (respectively) and other processes cannot start (Figure 4).

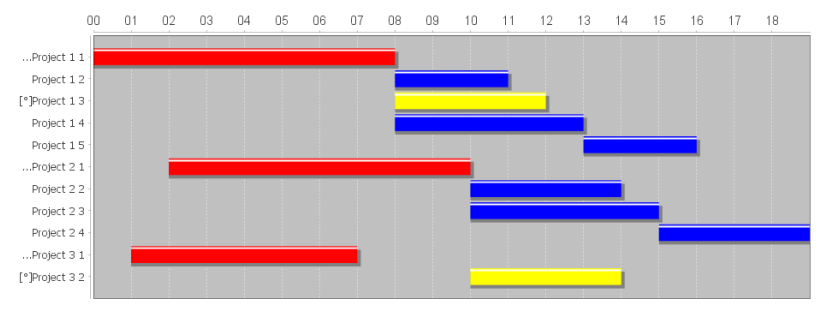

Figure 4: Order execution schedule - example with a look-ahead; decision on resource allocation made within deadline $t_{l}=5$.

\section{Summary and conclusions}

A dispatch system of managing renewable resources of a company should have three essential functions: informative, preventive and intervention. Based on the data collected and analysed from the sites concerning the progress of construction works, it should be possible to control the process progress and identify potential causes of untimely completion of work against the schedule, limitation of disturbances by the implementation of corrective measures and - first and foremost - implementation of process, organisation and management improvements and changes in the dispatch system.

The above examples illustrate the effect of resource allocation rules, options of blocking resources in particular building sites implemented in RRMSCC, and the scale of the planning horizon on the schedules of works in all considered projects. The decisions made using RRMSCC should follow the contractor's strategy and are expected to assure timely delivery of works, continuous resource utilisation, or to minimize the scope of subcontracted works.

The prerequisite of a dispatch system efficiency is to introduce a method of operating management of sites managed by a company, to establish dispatch services and provide them with an efficient computer-based system supporting their decisions, its continuous improvement and training of the managers. Implementation of the reference computer-based system can contribute to a more effective use of renewable resources owned by a contractor of construction works.

A further development of the RRMSCC system is planned to embrace implementing other rules of allocation renewable resources. New versions of the system should be able to import data generated by the scheduling software used in construction to facilitate implementing $R R M S C C$ in construction organizations.

Acknowledgement: This work was financially supported by Ministry of Science and Higher Education in Poland within the statutory research number S/63/2018. The author gratefully acknowledges the support.

\section{References}

[1] Ballard, G. (1997). Lookahead planning: the missing link in production control. Technical Report No. 97-3, Construction Engineering and Management Program, Civil and Environmental Engineering Department, University of California, Berkeley, CA 9472.

[2] Biruk, S., Jaśkowski, P., Czarnigowska, A. (2017). Modeling contractor's bidding decisions. Procedia Engineering, 182, 1-786.

[3] Chua, D.K.H., Shen, L.J., Bok, S.H. (2003). Constraint-based planning with integrated production scheduler over Internet. Journal of Construction Engineering and Management, 29(3), 293-301.

[4] Demeulemeester, E.L., Herroelen, W.S. (2002). Project scheduling. A research handbook. Kluwer Academic Publishers.

[5] Hejducki, Z. (2003). Scheduling model of construction activity with time couplings. Journal of Civil Engineering and Management, 9(4), 284-291.

[6] Howell, G. (1999, July 26-28). What is Lean Construction-1999. Proceedings of 6th IGLC Conference, California, Berkeley, 1-10.

[7] Jaśkowski, P. (2008). Designing the structure of a construction project operating system using evolutionary algorithm. Archives of Civil Engineering, LIV, 2, 371-394.

[8] Kanagasabapathi, B., Ananthanarayanan, K. (2005, September 7-9). A simulation model for resource constrained scheduling of multiple projects. Proceedings of the 21st Annual ARCOM Conference, SOAS, University of London. Association of Researchers in Construction Management, 2, 823-31.

[9] Kasprowicz, T. (2017). Quantitative assessment of construction risk. Archives of Civil Engineering, LXII, 2, 55-66.

[10] Krzemiński, M. (2017). The scheduling of construction work under the assumption of brigade multitasking. Procedia Engineering, 208, 63-68.

[11] Marcinkowski, R. (2007). Scheduling production of a construction company. Przegląd Budowlany, 2, $41-47$ (in Polish).

[12] Lidelöw, H., Simu, K. (2015). Understanding construction contractors and their operations strategies. Procedia Economics and Finance, 21, 48-56.

[13] Orihuela, P., Orihuela, J., Pacheco, S. (2016). Information and communications technology in construction: A proposal for production control. Procedia Engineering, 164, 150-157.

[14] Połoński, M., Pruszyński, K. (2013). Impact of baseline terms on the course of critical paths and time buffers in the modified Goldratt's method. Archives of Civil Engineering, 59(3), 313-320.

[15] Shi, J.J., Halpin, D.W. (2003). Enterprise resource planning for construction business management. Journal of Construction Engineering and Management, 129(2), 214-221. 
[16] Skorupka, D. (2008). Identification and initial risk assessment of construction projects in Poland. Journal of Management in Engineering, 24(3), 120-127.

[17] Sriprasert, E., Dawood, N.N. (2003). Multi-constraint information management and visualisation for collaborative planning and control in construction. Electronic Journal of Information Technology in Construction, 8, 341-366.
[18] Tang, P., Mukherjee, A. (2013, December 08 - 11). Construction schedule simulation for improved project planning: activity criticality index assessment. Proceedings of the 2013 Winter Simulation Conference, Washington, DC, USA, 3237-3248. 